\title{
Será fungo?
}

Diana Tomaz*

\section{RESUMO}

Estima-se que as infecções fúngicas superficiais afectem 20 a $25 \%$ da população mundial e a sua incidência continua a aumentar. A maioria é causada por dermatófitos, que são fungos que necessitam de queratina para crescer. As alterações produzidas por estes fungos designam-se de dermatofitoses, epidermofitias ou tinhas.

Em Medicina Geral e Familiar é habitual o clínico deparar-se com questões como: «Dr., apareceram-me umas manchas na pele, será um fungo?». Algumas vezes, particularmente em doentes com risco especial como os polimedicados, os diabéticos, os imunodeprimidos ou as crianças, torna-se difícil saber quando é adequado instituir terapêutica oral.

O presente artigo tem como objectivo efectuar uma breve revisão das dermatofitoses, com especial enfoque na sua abordagem terapêutica.

As tinhas classificam-se de acordo com a sua localização anatómica: tinea capitis no couro cabeludo, tinea pedis nos pés, tinea corporis no corpo, tinea cruris na região inguinal e tinea unguium nas unhas.

Um exame clínico cuidado é o primeiro e mais importante passo no diagnóstico das epidermofitias. No entanto, este pode ser estabelecido através de um dos diversos exames: microscopia com hidróxido de potássio, cultura, lâmpada de Wood e biópsia. Na prática clínica, a recolha de amostras para microscopia e cultura é aconselhada quando há necessidade de terapêutica oral, a infecção parece refractária ao tratamento inicial ou o diagnóstico é incerto.

Apesar do tratamento tópico ser suficiente, na maioria das dermatofitoses, a terapêutica oral é aconselhada nas tinhas do couro cabeludo, da barba e das unhas. Os antifúngicos tópicos do grupo das alilaminas possibilitam tratamentos mais curtos e taxas de cura maiores do que os antifúngicos do grupo dos azóis. A terbinafina, o itraconazol e o fluconazol são os fármacos mais utilizados para tratamento sistémico.

Palavras-chave: Dermatofitoses; Diagnóstico; Prevenção; Terapêutica; Cuidados de Saúde Primários.

\section{INTRODUÇÃO}

$\square$ stima-se que as infecções fúngicas superficiais afectem 20 a $25 \%$ da população mundial e a sua incidência continua a aumentar. ${ }^{1}$ A maioria é causada por dermatófitos, que são fungos que necessitam de queratina para crescer, o que restringe o seu crescimento à pele, unhas e cabelo, poupando as mucosas. ${ }^{1-4}$ As alterações produzidas por estes fungos designam-se de dermatofitoses, epidermofitias ou tinhas (do latim tinea). ${ }^{5}$

As espécies do género Microsporum, Trichophyton e Epidermophyton são os patogénios mais comuns..$^{2-3,6-7}$ Em Portugal, entre 1972 e 1980, encontravam-se como espécies etiológicas mais frequentes: T. rubrum (50\%), T. mentagrophytes (24\%), E. floccosum (9\%) e T. megninii $(4 \%) .{ }^{8}$ Menos frequentemente, as infecções superficiais da pele são causadas por fungos não dermatófi-

*Interna do Internato Médico de Medicina Geral e Familiar; USF Conde de Oeiras. tos (p.e. Malassezia furfur na pitiríase versicolor) e espécies de Candida. ${ }^{2}$

Em Medicina Geral e Familiar é habitual o clínico deparar-se com questões como: «Dr., apareceram-me umas manchas na pele, será um fungo?». Algumas vezes, particularmente em doentes com risco especial como os polimedicados, os diabéticos, os imunodeprimidos ou as crianças, torna-se difícil saber quando é adequado instituir terapêutica oral. Deste modo, tendo em conta a frequência das infecções fúngicas da pele, nomeadamente das dermatofitoses, o presente artigo tem como objectivo efectuar uma breve revisão destas, com especial enfoque na sua abordagem terapêutica.

As epidermofitias são adquiridas directamente pelo contacto com humanos infectados ou animais, ou indirectamente através da exposição a células descamadas em solos contaminados ou fómitos (p.e. escovas, chapéus)..$^{2-3,9}$ 
Factores genéticos e doenças sistémicas como a diabetes contribuem para uma maior susceptibilidade à infecção, assim como factores locais como a humidade, a ausência de luminosidade e a fricção, ao conduzirem à maceração cutânea. ${ }^{10} \mathrm{~A}$ imunossupressão terapêutica ou iatrogénica facilita a recidiva e a manutenção da doença ou o aparecimento de formas atípicas. ${ }^{5}$

As tinhas classificam-se de acordo com a sua localização anatómica: tinea capitis no couro cabeludo, tinea pedis nos pés, tinea corporis no corpo, tinea cruris na região inguinal e tinea unguium nas unhas., ${ }^{3,710-11}$

Embora ambos os sexos sejam afectados, os homens tendem a apresentar tinhas do pé e das pregas inguinais mais frequentemente. ${ }^{4}$ Após a puberdade, o género masculino também adquire tinhas das unhas com maior facilidade. ${ }^{4}$

Ao exame objectivo é típica a presença dum bordo activo, que corresponde a um padrão inflamatório caracterizado por maior eritema e descamação nos limites da lesão e, ocasionalmente, pela formação de bolhas. ${ }^{2} \mathrm{~A}$ regressão central da lesão como tentativa natural de cura por parte do organismo pode estar presente, permitindo distinguir as tinhas de outras erupções papulo-descamativas como a psoríase e o líquen plano, nas quais a resposta inflamatória é uniforme em toda a lesão. ${ }^{2}$

A localização das lesões também facilita a identificação do agente patogénico. ${ }^{2}$ Desta forma, a hipótese de dermatofitose pode ser excluída se existir envolvimento de uma mucosa adjacente a uma erupção cutânea com eritema e descamação. ${ }^{2}$ Nestas situações, o diagnóstico mais provável é a candidíase. ${ }^{2}$

\section{Tinea capitis}

A tinha do couro cabeludo é uma infecção do escalpe e dos folículos pilosos, cuja transmissão é facilitada por maus hábitos de higiene. ${ }^{2,12}$ É a infecção fúngica mais frequente nas crianças. ${ }^{1-4,11-13}$ Após a queda, os cabelos afectados podem albergar organismos viáveis durante mais de um ano. ${ }^{2,11}$

Clinicamente, as tinhas do couro cabeludo podem apresentar-se de 3 formas distintas:

- Tricofítica - associada ao género Trichophyton, caracteriza-se por áreas de alopécia, múltiplas, dispersas e monomorfas. ${ }^{5}$ Pode adquirir o aspecto de «alopécia de cotos negros» devido aos cabelos parti- dos junto ao escalpe. .,4-5,9,11 $^{2,4}$

- Microspórica-é constituída por áreas de alopécia de dimensões variáveis, definidas e regulares, com tendência a confluírem, por vezes acompanhadas de outras mais pequenas, com uma superfície descamativa (Figura 1). ${ }^{5,9} \mathrm{O}$ agente etiológico é do género Microsporum. ${ }^{5,9}$

- Favosa - originada essencialmente pelo T. Schoenleinii é, actualmente, rara em Portugal. Caracteriza-se pela chamada escútula: crosta bem delimitada, redonda e deprimida no centro, por vezes acompanhada de odor a urina de rato. ${ }^{5,9} \mathrm{~A}$ sua evolução é crónica, sendo a alopécia quase total em casos avançados. ${ }^{5,9}$ Pode apresentar-se sob a forma eritematosa folicular ou descamativa, esta última com aspecto próximo da dermatite seborreica, tomando ambas a designação de falsas tinhas amiantáceas. ${ }^{5}$

A tinha do couro cabeludo pode conduzir a uma resposta imune mediada por células designada de kerion. ${ }^{2,11}$ Nestas circunstâncias, o escalpe apresenta lesões inflamatórias, supurativas e habitualmente pouco dolorosas, podendo acompanhar-se de adenomegalias cervicais e occipitais..$^{2,3,9,11}$ Embora o kerion tenda para a cura espontânea, pode originar alopécia cicatricial, pelo que deve ser referenciado para consulta de dermatologia. ${ }^{5,9,14}$

O diagnóstico diferencial inclui: alopécia areata, tricotilomania, alopécia de tracção, dermatite seborreica e psoríase. ${ }^{2-3,14}$

De acordo com um estudo de Hubbard, o diagnóstico de tinea capitis foi confirmado em $92 \%$ das crianças

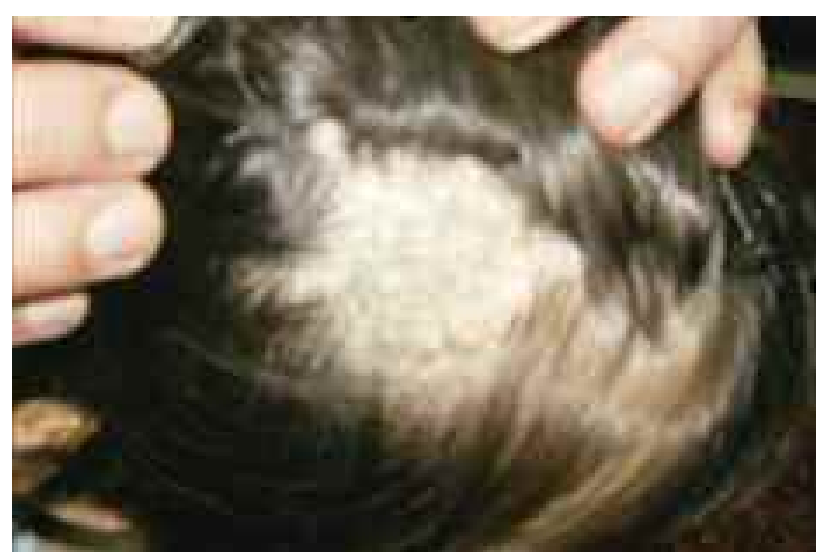

Figura 1. Tinea capitis. 
que apresentavam pelo menos três dos seguintes critérios: descamação, prurido do couro cabeludo, adenopatia occipital e alopécia. ${ }^{2,15}$

O tratamento tópico não é eficaz na tinea capitis, sendo a terapêutica sistémica necessária para penetrar nos folículos capilares..$^{2-3,14,16}$

Apesar da griseofulvina ser frequentemente considerada o tratamento de eleição em crianças, esta não se encontra disponível em Portugal. ${ }^{3}$

Em alternativa, a terbinafina $(62,5 \mathrm{mg} / \mathrm{dia}$ em crianças com peso inferior a $20 \mathrm{~kg}$; $125 \mathrm{mg} /$ dia em crianças pesando entre 20 e $40 \mathrm{~kg}$; $250 \mathrm{mg} /$ dia nas com peso superior a $40 \mathrm{~kg}$ ) durante quatro semanas demonstrou ser tão eficaz como a griseofulvina nas infecções a Trichophyton, mas não no género Microsporum. ${ }^{3,12} \mathrm{O}$ tratamento com terbinafina está aprovado em crianças a partir dos 2 anos. ${ }^{3}$ Devido à possibilidade de toxicidade hepática, a função hepática deve ser avaliada antes do início da terapêutica e no seguimento (Quadro I).,11

Ambos os esquemas contínuo ( $5 \mathrm{mg} / \mathrm{kg} /$ dia durante 4 semanas, num máximo de $200 \mathrm{mg} /$ dia) e pulsado ( $5 \mathrm{mg} / \mathrm{kg} /$ dia numa semana do mês por 2-4 meses) de itraconazol em comprimidos podem ser usados no tratamento da tinha do couro cabeludo. ${ }^{6,12,16} \mathrm{~A}$ solução oral não deve ser usada em crianças devido ao risco de diarreia pelo excipiente ciclodextrina. ${ }^{13}$

Alguns estudos revelam que a terapêutica com fluconazol $6 \mathrm{mg} / \mathrm{kg} /$ dia durante $2-3$ semanas é igualmente eficaz. ${ }^{16}$

A utilização de antifúngicos tópicos como champôs com cetoconazol, sulfureto de selénio, iodopovidona ou piritionato de zinco, aplicados com a periodicidade de lavagem habitual, pode servir de terapêutica adjuvante com ou sem anti-fúngicos orais para prevenir a reinfecção ou para tratar os portadores assintomáticos. ${ }^{2,6,12,16}$

A fim de prevenir a reinfecção ou transmissão, é igualmente importante eliminar, desinfectar com anti-sépticos (p.e. cloroexidrina a 2\%) ou lavar com lixívia objectos que possam ter fungos alojados tais como escovas, almofadas, chapéus, lençóis e tesouras.,14-16

\section{Tinea corporis}

A tinha do corpo é uma dermatofitose que afecta a pele do tronco e das extremidades, excluindo o cabelo, as unhas, a região inguinal, as palmas das mãos e as plantas dos pés. ${ }^{4,711}$ Apesar de se poder desenvolver em qualquer parte do corpo, ocorre, geralmente, nas áreas cutâneas expostas. ${ }^{4}$

Esta dermatofitose é maioritariamente causada por espécies de Tricophyton, mais especificamente o T.rubrum, o dermatófito mais comum em países desenvolvidos. ${ }^{1,3-4}$

A existência de história pessoal ou de contacto próximo com tinha do couro cabeludo ou do pé são factores de risco importantes para o desenvolvimento de $t i$ nea corporis. ${ }^{4}$

A tinha do corpo manifesta-se tipicamente como uma ou múltiplas lesões anulares descamativas, com atenuação central e bordo ligeiramente elevado e eritematoso (Figura 2)..$^{2-4,7,11,17} \mathrm{O}$ bordo pode apresentar pústulas ou pápulas foliculares e a presença de prurido é variável. ${ }^{2,4}$

O diagnóstico diferencial faz-se com: eczema numular, pitiríase rosada, doença de Lyme, pitiríase versicolor, dermatite de contacto, granuloma anular e psoríase. $^{2}$

O uso prévio de corticosteróides pode alterar a aparência das lesões, situação designada como tinea incognito. $^{4,10}$

O tratamento tópico normalmente é suficiente para a cura, recomendando-se a aplicação do antifúngico tópico sobre a lesão e até $2 \mathrm{~cm}$ na área circundante às

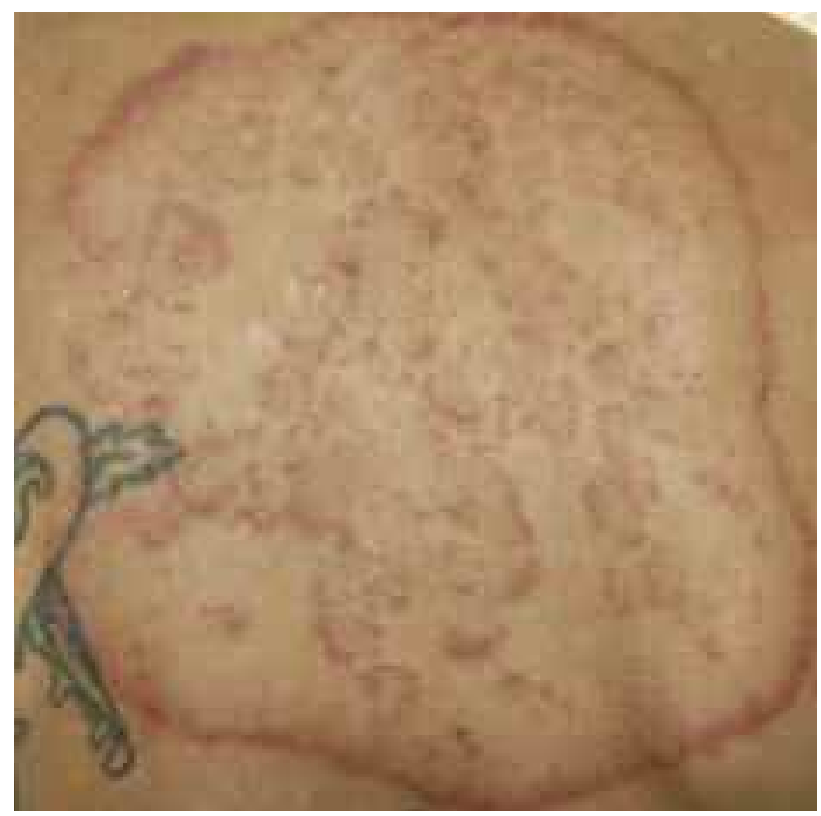

Figura 2. Tinea corporis 


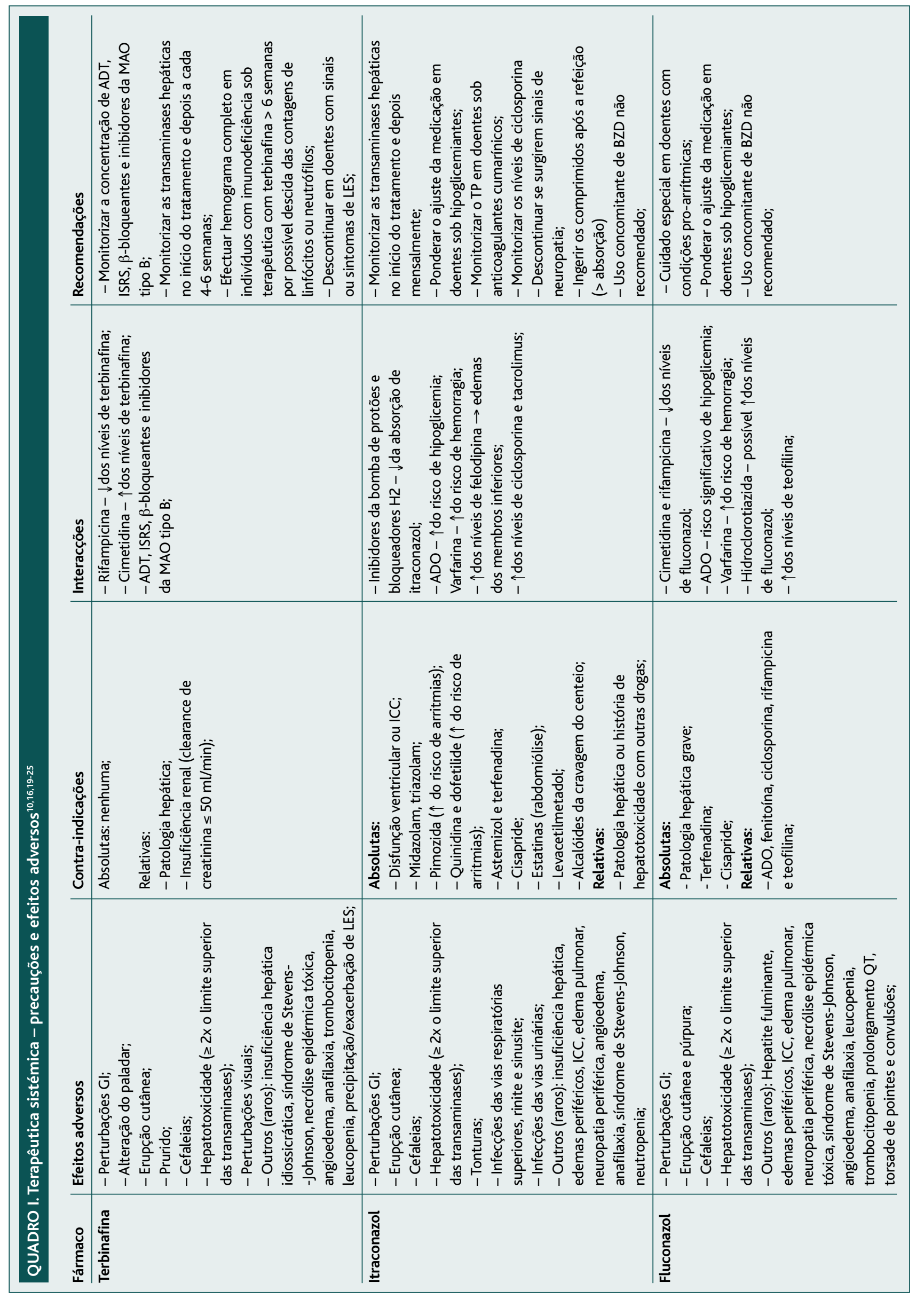

99

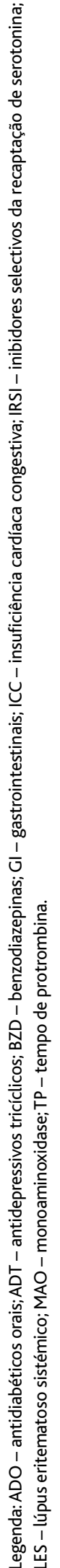


lesões, uma a duas vezes/dia, até uma semana após o seu desaparecimento., ${ }^{3,71}$ Os antifúngicos tópicos para a tinea corporis incluem terbinafina, butenafina, econazol, miconazol, cetoconazol, clotrimazol, itraconazol, sertoconazol, omoconazol e ciclopirox. ${ }^{7,11,16}$ Estudos sugerem que os dois primeiros são mais eficazes que $o$ miconazol e o clotrimazol graças às suas propriedades fungicidas. ${ }^{3}$

Todavia pode recorrer-se às formulações orais em indivíduos com infecção grave, quando não há resposta aos tópicos, há áreas extensas envolvidas, ou a infecção é crónica ou recorrente. ${ }^{4,7,16-17}$ Nestas situações pode utilizar-se um dos seguintes: itraconazol (100 $\mathrm{mg} /$ dia durante 2 semanas), terbinafina $(250 \mathrm{mg} / \mathrm{dia}$ durante 2-4 semanas) ou fluconazol (150-300mg uma vez/semana durante 2-4 semanas). ${ }^{16}$ Estes são preferíveis ao cetoconazol devido aos potenciais efeitos adversos hepáticos. ${ }^{16}$

Os doentes devem ser aconselhados a evitar o contacto directo com outros indivíduos e a partilha de toalhas ou vestuário para prevenir a transmissão, enquanto não tiverem iniciado o tratamento. ${ }^{11}$

\section{Tinea barbae}

A tinha da barba atinge a pele e os pêlos faciais da zona da barba. ${ }^{2,11}$

Afecta homens adultos e mulheres hirsutas. Em geral, ocorre em indivíduos que trabalham em quintas, uma vez que o agente causal é transmitido pelo contacto com os animais. ${ }^{2}$

A tinea barbae pode originar descamação, pústulas foliculares e eritema. ${ }^{2}$ Pode, também, existir alopécia no centro das lesões. ${ }^{4,11}$

O diagnóstico diferencial abrange as seguintes condições: foliculite bacteriana, dermatite perioral, pseudofoliculite da barba, dermatite de contacto e herpes simplex. ${ }^{2}$ Quando se retira um pêlo da barba nesta epidermofitia não se desencadeia dor, contrariamente ao que acontece nas infecções bacterianas, o que pode ajudar no diagnóstico. ${ }^{2}$

Tal como na tinea capitis, a terapêutica é oral e mantida até duas a três semanas após a resolução das lesões cutâneas. ${ }^{2} \mathrm{O}$ tratamento envolve o barbear completo. ${ }^{11}$

\section{Tinea faciei}

A tinha da face surge na região da face sem barba. ${ }^{2}$

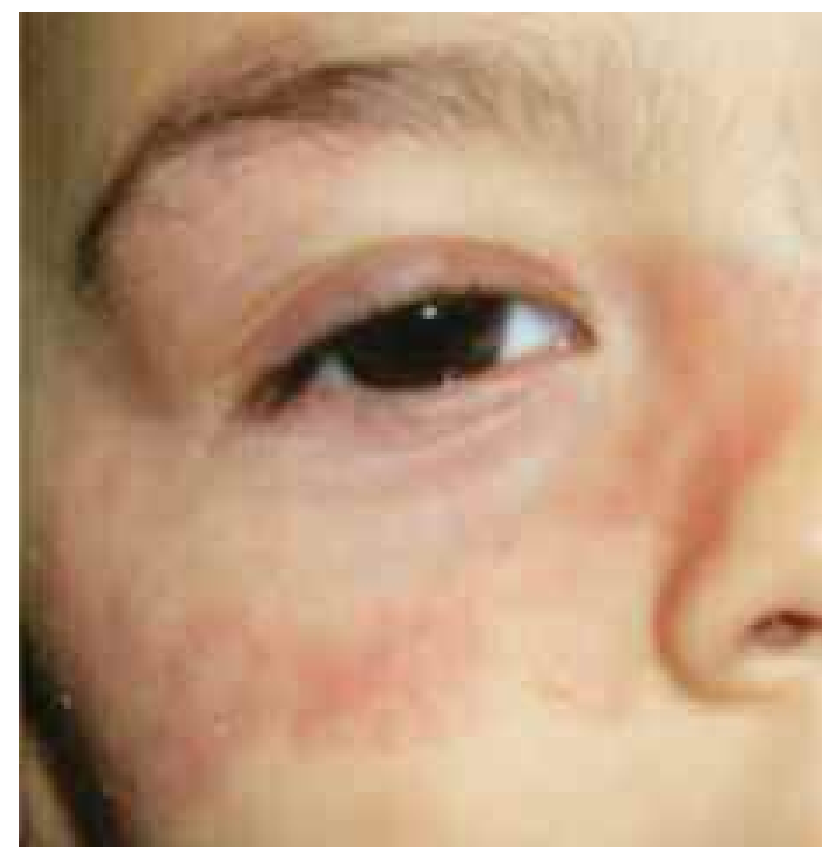

Figura 3. Tinea faciae.

Apresenta-se sob a forma de placas avermelhadas anulares ou arredondadas (Figura 3 ). ${ }^{2}$ No entanto, a coloração pode ser indistinta, principalmente em peles muito pigmentadas, e a descamação ou os bordos elevados estarem ausentes. ${ }^{2}$

$\mathrm{O}$ doente pode queixar-se de prurido e ardor que agravam com a exposição solar. ${ }^{2}$

O diagnóstico diferencial compreende: dermatite seborreica, rosácea, lúpus eritematoso discóide e dermatite de contacto. ${ }^{2}$

O tratamento é semelhante ao da tinea corporis. ${ }^{2}$

\section{Tinea cruris}

A tinea cruris é uma infecção dermatófita da região inguinal que ocorre predominantemente no sexo masculino. ${ }^{2-5,11,17}$ Contudo, tem-se vindo a tornar mais frequente em mulheres pós-puberdade com excesso de peso ou que vestem calças apertadas. ${ }^{3}$

A tinea cruris encontra-se frequentemente associada à tinea pedis, uma vez que o vestuário é contaminado ao passar pelos pés, entrando posteriormente em contacto com a região inguinal. ${ }^{2,4}$ Sendo as duas infecções habitualmente concomitantes, a etiologia de ambas é comum (T. rubrum, T mentagrophytes e E. floccosum). ${ }^{3}$ 
Clinicamente, afecta a região proximal e interna das coxas, podendo estender-se à região glútea e ao abdómen, poupando, no entanto, o escroto (Figura 4), ${ }^{2,4,10-11,17}$ Se o escroto estiver envolvido ou se existirem erosões ou pústulas satélite, a candidíase das pregas deve ser considerada. $^{4}$

Caracteriza-se por áreas eritematosas, maceradas, com bordos elevados e descamativos, acompanhados de pústulas e vesículas..$^{2-4,11-17}$ Os doentes podem queixar-se de prurido e ardor. ${ }^{2-3,11}$

Deve efectuar-se o diagnóstico diferencial com: candidíase das pregas, eritrasma, intertrigo mecânico, psoríase e dermatite seborreica. ${ }^{2,17}$

O tratamento é semelhante ao da tinea corporis. ${ }^{16}$ Os corticosteróides tópicos em baixa dose (p.e. 2,5\% de hidrocortisona) podem ser usados como adjuvantes nos primeiros dias, para reduzir a inflamação da pele envolvida. $^{2,11}$

Os pés devem ser avaliados como fonte primária de infecção e tratados quando existe dermatofitose..$^{2-5}$

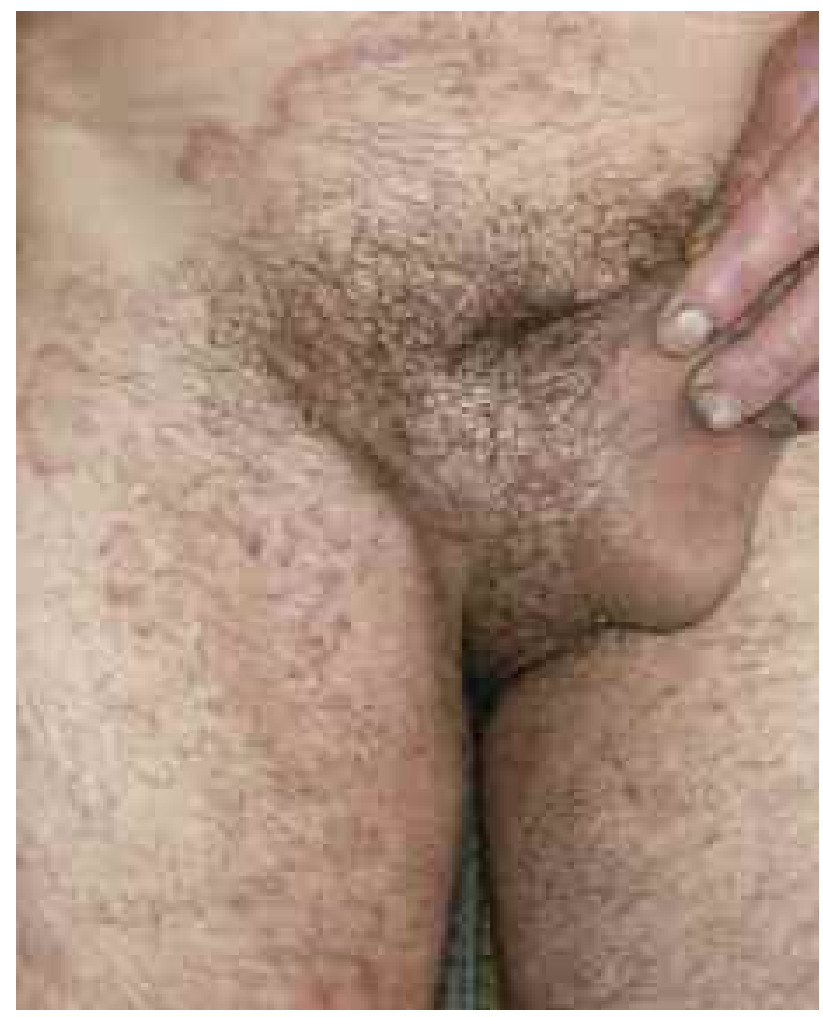

Figura 4. Tinea cruris.
A educação do doente a fim de evitar a exposição prolongada local à humidade e de manter a área afectada seca é importante. ${ }^{2,11} \mathrm{O}$ uso de vestuário pouco apertado, a perda de peso e a lavagem de roupas contaminadas são medidas que previnem, igualmente, a re-

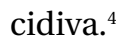

\section{Tinea pedis}

A tinha do pé é a dermatofitose mais frequente. ${ }^{1,4,7,16}$ A sua incidência, juntamente com a das onicomicoses, tem vindo a crescer como resultado não só de mudanças no estilo de vida que incluem a urbanização, a utilização de banhos comuns e de calçado oclusivo; mas também do aumento da incidência da diabetes e da infecção pelo VIH..$^{1,16}$

É comum em adolescentes, mas rara em crianças antes da puberdade. ${ }^{3,18}$

A forma interdigital, caracterizada pela presença de fissuras, maceração e descamação dos espaços interdigitais, é a mais habitual. ${ }^{2,4,6,11,18}$ Os doentes queixam-se de prurido e ardor. ${ }^{2}$ Outra apresentação, normalmente causada pelo $T$ rubrum, pode afectar as regiões plantares com espessamento e descamação, acompanhando-se de eritema e hiperqueratose dos calcanhares, plantas e faces laterais dos pés - tipo «moccasin» (Figura 5). 2,6-7 Pode ainda surgir sob a forma vesiculo-bulhosa constituída por vesículas, pústulas e, por vezes, bolhas geralmente na região plantar dos pés. ${ }^{2-3,6}$

O diagnóstico diferencial inclui a dermatite de contacto, o eczema e a psoríase. ${ }^{2}$

O tratamento primário consiste na aplicação de antifúngicos tópicos uma a duas vezes por dia, resolvendo-se a infecção após duas a quatro semanas. ${ }^{7,11,16}$ As formulações de terbinafina, butenafina, miconazol, econazol, cetoconazol, clotrimazol, oxiconazol e ciclopirox são os tratamentos tópicos mais utilizados..$^{16} \mathrm{O}$ creme de cetoconazol a $2 \%$ pode melhorar a adesão terapêutica e, subsequentemente, a eficácia ao permitir apenas uma aplicação diária. ${ }^{16}$ Existe uma maior taxa de cura com a família das alilaminas tópicas do que com os azóis. ${ }^{10,16}$

Alguns agentes tópicos, como a ciclopiroxolamina a $1 \%$ e o nitrato de miconazol a $1 \%$, proporcionam uma actividade antibacteriana e podem ser preferíveis quando há suspeita de superinfecção bacteriana. ${ }^{16}$

A infecção crónica ou recidivante pode implicar tra- 


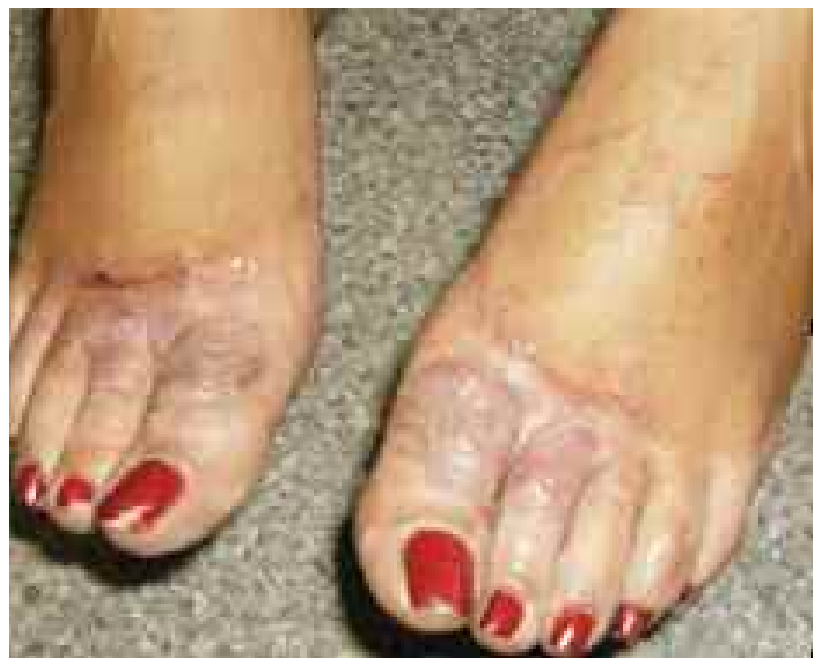

Figura 5. Tinea pedis em «moccassin».

tamento oral, especialmente se os agentes tópicos falharam, ou quando a área afectada é extensa. ${ }^{2,3,15-16,18} \mathrm{~A}$ terbinafina $(250 \mathrm{mg} /$ dia durante 2-6 semanas) ou itraconazol (100mg/dia durante 1 mês, 400mg/dia durante 1 semana ou $200 \mathrm{mg}$ /dia durante 2-4 semanas) orais parecem ser os fármacos mais eficazes. ${ }^{16} \mathrm{~A}$ terapêutica com fluconazol (150mg/semana durante 2-6 semanas) também é uma opção. ${ }^{16}$

Uma vez que a celulite estreptocócica é uma complicação possível, pode ser necessária a adição de um antibiótico tópico ou oral quando houver sinais de sobre-infecção bacteriana. ${ }^{2}$

A recidiva é comum, particularmente se houver onicomicose associada, que deve ser tratada. ${ }^{2}$

A prevenção da reinfecção é essencial, sendo recomendável a utilização de chinelos em piscinas e balneários públicos, o controlo da hiperhidrose com pós antimicóticos e/ou antimicrobianos e a desinfecção dos sapatos com sprays anti-sépticos. ${ }^{2},{ }^{6,16}$ Os pés devem ser secos cuidadosamente e o calçado fechado evitado ou alternado a cada 2-3 dias a fim de reduzir a humidade local. ${ }^{6,10,16,18}$

\section{Tinea manuum}

A tinha da mão é a infecção fúngica de uma ou, ocasionalmente, de ambas as mãos. ${ }^{2}$ Ocorre frequentemente em indivíduos com tinea pedis. ${ }^{2,4}$

Clinicamente, caracteriza-se por hiperqueratose e desidratação da superfície palmar da mão (Figura 6). ${ }^{2}$
Quando as unhas das mãos estão envolvidas, podem estar presentes vesículas e descamação, semelhantes ao eczema desidrótico. ${ }^{2}$

No que concerne ao diagnóstico diferencial, este abrange o já referido eczema desidrótico, a dermatite de contacto, a psoríase e as calosidades. ${ }^{2}$

Os tratamentos da tinha do pé são utilizados eficazmente na tinha da mão. ${ }^{16}$ Os emolientes com ácido láctico são eficazes no tratamento da tinea manuum. ${ }^{2}$

As recidivas são comuns quando as onicomicoses ou a tinea pedis associadas não são resolvidas. ${ }^{2}$

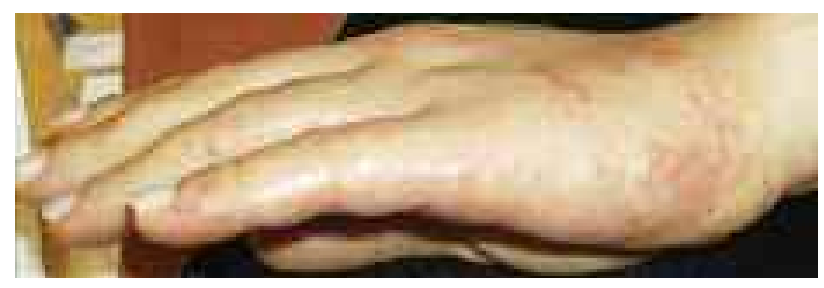

Figura 6. Tinea manum.

\section{Tinea unguium}

A onicomicose é uma distrofia ungueal que pode ser causada por qualquer espécie de fungo, dermatófito ou não dermatófito. ${ }^{2-5,13,19-21}$ Representa a afecção mais comum das unhas (mais de 50\%) e os dermatófitos são responsáveis por $90 \%$ dos casos. ${ }^{4,19-22}$ As espécies T. rubrum, Tmentagrophytes e E.floccosum são os principais agentes etiológicos. ${ }^{4,19} \mathrm{~A}$ sua prevalência aumenta com a idade, atingindo os $20 \%$ nos indivíduos com mais de 60 anos. $^{21,22}$

As onicomicoses constituem um desafio para o clínico na medida em que implicam longos períodos de tratamento, potenciais efeitos sistémicos da medicação e uma recidiva frequente. ${ }^{4}$

A humidade, o calçado oclusivo, o trauma repetido da unha, a predisposição genética e a presença de patologia concomitante, como a diabetes, o défice de circulação periférica e a infecção pelo VIH ou outras formas de imunossupressão são factores que contribuem para a doença. . $^{6,19,21}$

O termo Tinea unguium diz respeito especificamente à infecção da unha por dermatófitos. ${ }^{4}$ Afecta mais frequentemente os homens do que as mulheres $\mathrm{e}$ encontra-se associada à tinha do pé crónica. ${ }^{4}$ 
A tinha da unha pode exibir 3 padrões distintos de acordo com a porta de entrada do fungo na unha:

- distal/ lateral subungueal, a apresentação mais comum, caracterizada por unhas amarelas acompanhadas de hiperqueratose subungueal e onicólise, e que normalmente se inicia a partir da tinha do pé existente na pele circundante;

- superficial - leuconíquia dermatofítica-provocada pela inoculação da lamina dorsal das unhas e que surge como manchas brancas, opacas, bem delimitadas, que crescem no sentido do bordo livre;

- subungueal proximal, associada a hospedeiros imunodeprimidos. ${ }^{4-5,19-24}$

As infecções das unhas dos pés são largamente mais comuns do que as das mãos e apenas raramente ocorre tinha da unha da mão sem infecção concomitante das unhas dos pés. ${ }^{4}$ Embora possa afectar uma única unha, geralmente estão envolvidas múltiplas unhas em uma ou ambas as mãos ou pés. ${ }^{4}$ Contudo, é raro que todas as unhas estejam alteradas, o que facilita a distinção da psoríase. ${ }^{5}$

As alterações clínicas vão desde pequenas manchas esbranquiçadas até ao espessamento com destruição da lâmina da unha e à hiperqueratose subungueal. ${ }^{5} \mathrm{Ob}$ serva-se discromia, de cor esbranquiçada ou amarelada, superfície irregular, por vezes baça, espessamento, fendilhação e descolamento que chega a separar a unha em duas lâminas (Figura 7). ${ }^{5}$

A tinea unguium e as onicomicoses causadas por fungos não dermatófitos apresentam uma clínica e um tratamento semelhantes. Deste modo, é fundamental distingui-las de outras patologias: trauma crónico, psoríase, líquen plano, tumor do leito ungueal, doença vascular periférica e síndrome das unhas amarelas., ${ }^{2,19,21,23,25-26}$

A existência de tinea pedis ou de história desta no ano antecedente associada a alterações da coloração da unha é altamente preditiva do diagnóstico de infecção fúngica da unha. ${ }^{25}$

O método de diagnóstico padrão é a existência de um resultado positivo no exame microscópico e a cultura de material ungueal..$^{20,25}$ Contudo, de acordo com um estudo europeu, os médicos de família e os dermatologistas usualmente iniciam tratamento na ausência de exame confirmatório. ${ }^{25}$

No que concerne ao tratamento, as unhas das mãos exibem taxas de sucesso superiores às dos pés devido

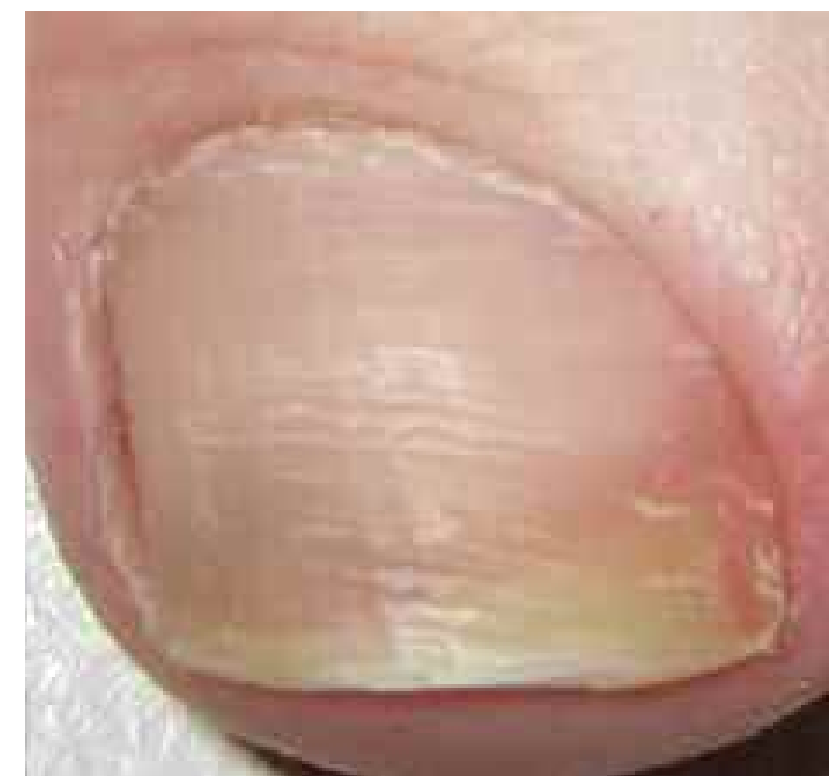

Figura 7. Tinea unguium do dedo I do pé.

à sua maior velocidade de crescimento, implicando regimes terapêuticos mais curtos. ${ }^{16}$

A tinea unguium, especialmente dos pés, é difícil de erradicar e os agentes tópicos demonstram uma baixa eficácia., ${ }^{2,10,21}$ No entanto, a aplicação de tópicos pode ser apropriada nas infecções ligeiras a moderadas (envolvimento $\leq 50 \%$ do bordo distal) em que não há lesão da matriz e poucas unhas (3-4) estão afectadas., 6,16,20-21 Quando a terapêutica sistémica está contra-indicada é, igualmente, adequado recorrer aos agentes tópicos em monoterapia. ${ }^{19-21,25}$

A amorolfina (1 vez/semana durante 6-12 meses) e a ciclopiroxolamina ( $1 \mathrm{vez} /$ dia durante 48 semanas) em verniz demonstram uma boa penetração na unha e estão aprovadas no tratamento das onicomicoses em monoterapia. ${ }^{16,19}$ Previamente a cada utilização de amorolfina, deve proceder-se à aplicação de álcool na superfície da unha para remover os vestígios de verniz. ${ }^{22}$

O tioconazol tópico (2 vezes/dia durante 6-12 meses) em monoterapia ou diferentes combinações com a amorolfina e a ciclopiroxolamina também podem ser

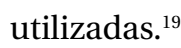

Outras formulações tópicas como a terbinafina podem ser úteis como adjuvantes em infecções graves sob terapêutica oral com terbinafina, ou quando existe perioníquia. ${ }^{16}$ 
Frequentemente, a aplicação de tópicos é insuficiente e é necessário ponderar o tratamento sistémico. ${ }^{10}$

Antes de se proceder ao tratamento devem-se ter em conta diversos factores: as comorbilidades do doente, as interacções com outros medicamentos, os efeitos adversos, a idade do doente, a probabilidade de adesão à terapêutica e os custos monetários. ${ }^{19,27}$

O valor do benefício estético isolado deve ser pesado contra os custos e riscos da terapêutica oral prolongada. ${ }^{10}$ No entanto, as onicomicoses começam a ser vistas como mais do que um mero problema estético. ${ }^{16,18}$ Os indivíduos afectados podem sentir-se incomodados com a condição, temer situações de maior intimidade, evitar o contacto com os parceiros ou apresentar dor durante a actividade física. ${ }^{27}$

Apesar da griseofulvina estar aprovada no tratamento da tinea unguium, a sua afinidade para a queratina é baixa, obrigando a terapêuticas prolongadas. ${ }^{13,16}$ A sua eficácia no tratamento das onicomicoses também é baixa. ${ }^{13,16} \mathrm{O}$ uso de cetoconazol não é recomendado devido à potencial toxicidade hepática e à existência de tratamentos orais alternativos..$^{16,23}$

Os triazóis (itraconazol e fluconazol) e as alilaminas (terbinafina) têm substituído a griseofulvina e o cetoconazol como tratamentos de primeira linha, pois oferecem períodos de tratamento mais curtos, maiores taxas de cura e menos recidivas. ${ }^{16,23,27}$

A terapêutica das onicomicoses com terbinafina é feita na dose de $250 \mathrm{mg}$ /dia durante 6 semanas (unhas das mãos) ou 12 semanas (unhas dos pés). ${ }^{16,20-21,23,28}$ Este fármaco tem demonstrado uma eficácia superior ao itraconazol e ao fluconazole vários estudos em adultos estabeleceram a terbinafina como primeira escolha no tratamento das tinhas das unhas., $3,6,20-22$

O itraconazol pode ser feito em regime contínuo (200 $\mathrm{mg} /$ dia durante 6 semanas nas unhas das mãos e 12 nas dos pés) ou pulsado (200mg 2 vezes/dia durante 1 semana, seguidos de 3 semanas de intervalo), implicando dois pulsos no caso das unhas da mão e três nas unhas do pé. ${ }^{16,19-21,23} \mathrm{O}$ tratamento pulsado é tão eficaz como o contínuo, envolve menos efeitos adversos e metade do custo. ${ }^{24}$

O fluconazol é utilizado na dose de 150-300mg uma vez por semana até a unha ganhar uma aparência normal (3-6 meses nas unhas das mãos e 9-12 meses nas unhas dos pés). ${ }^{16}$
A utilização de agentes tópicos concomitantemente com a terapêutica sistémica apresenta uma maior efi-

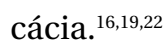

Quando existe tinea pedis concomitante esta deve ser tratada. $16,23,25$

Mesmo após o sucesso do tratamento, a recidiva é comum. ${ }^{10,16}$

A onicomicose lateral, o espessamento do leito ungueal, as estrias longitudinais e a presença de dermatofitoma ou de distrofia total da unha são factores preditivos de uma resposta reduzida à terapêutica sistémica. ${ }^{22,26}$

Em casos resistentes, a avulsão das unhas afectadas constitui um recurso, mas não evita uma eventual recidiva. ${ }^{5}$ A remoção não traumática das unhas é preferível à remoção cirúrgica que pode ser dolorosa e afectar permanentemente o leito ungueal. ${ }^{16,19} \mathrm{O}$ penso oclusivo com pomada de ureia a $40 \%$ durante duas semanas permite, em regra, a remoção da unha, sendo tão eficaz como a remoção cirúrgica. ${ }^{5,19,27}$

É importante esclarecer o doente acerca da morosidade do sucesso do tratamento, da necessidade de seguimento a longo prazo para identificação precoce de eventuais recidivas e de que a unha poderá não retomar o seu aspecto habitual após a erradicação da infecção. ${ }^{16,21,28}$

A utilização de meias de algodão e o corte frequente das unhas são medidas preventivas importantes.,6,6,19 Os doentes devem evitar andar descalços em piscinas e balneários públicos e devem secar cuidadosamente os pés após o banho. ${ }^{4,6-7,16,19,21,23,27}$

\section{Os idosos}

Os idosos apresentam factores de risco específicos que conduzem a uma fraca resposta ao tratamento das onicomicoses, incluindo: distrofia ungueal frequente, crescimento lento das unhas e maior prevalência de doença vascular periférica, imunodepressão, diabetes mellitus e trauma físico. ${ }^{22} \mathrm{~A}$ má adesão terapêutica, higiene e escolha do calçado também desempenham um papel importante. ${ }^{22}$

As onicomicoses em idosos diabéticos devem ser tratadas para prevenir infecções bacterianas secundárias e as suas subsequentes complicações. ${ }^{22}$

A terbinafina é a droga de escolha nas onicomicoses, uma vez que está associada a maiores taxas de cura mi- 
cológica, menor número de interacções, interacções de menor gravidade e a um custo inferior. ${ }^{22,29}$

O desbridamento adjuvante pode melhorar a probabilidade de cura, comparativamente à terbinafina isolada. ${ }^{22}$

A utilização de vernizes não é prática nos idosos devido à frequência de aplicação recomendada, à necessidade de desbridamento contínuo das unhas afectadas e à duração prolongada do tratamento..$^{22}$ Contudo, estes podem ser uma boa opção em monoterapia em doentes com onicomicoses superficiais ou em combinação com a terapêutica sistémica em indivíduos com condições que predispõem a uma resposta reduzida ao tratamento ou à recidiva. ${ }^{22}$ Além dos factores a ter em conta em adultos e idosos anteriormente enumerados, a presença de envolvimento da unha superior a $75 \% \mathrm{em}$ idosos contribui, igualmente, para uma menor resposta terapêutica. ${ }^{22}$

\section{As crianças}

Embora as onicomicoses afectem predominantemente os adultos, a incidência em crianças tem vindo a aumentar. ${ }^{30}$

Contrariamente aos adultos, em crianças pequenas ( $<7$ anos) a frequência de onicomicoses das unhas das mãos pode ser superior à dos pés. ${ }^{30}$

No que concerne ao tratamento, a aplicação de vernizes pode ser suficiente nos casos de onicomicose distal/ lateral leve a moderada ou de onicomicose superficial. ${ }^{30}$

A terbinafina $(62,5 \mathrm{mg} /$ dia em crianças com peso < 20kg; $125 \mathrm{mg} /$ dia em crianças com 20-40kg; e $250 \mathrm{mg} /$ dia nas com peso $>40 \mathrm{~kg}-6$ semanas nas unhas das mãos e 12 nas dos pés), o itraconazol ( $5 \mathrm{mg} / \mathrm{kg} / \mathrm{dia}$ durante 1 semana/ mês - 2 semanas nas unhas das mãos e 3 nas dos pés) e o fluconazol (3-6mg/ $\mathrm{kg}$ uma vez/ semana durante 12-16 semanas nas unhas das mãos e 18-26 nas dos pés) constituem as melhores opções de terapêutica sistémica nos doentes em idade pediátrica. ${ }^{13,19}$ São habitualmente bem tolerados, seguros e envolvem poucos efeitos adversos. ${ }^{19}$ Estes antifúngicos apresentam resultados superiores à griseofulvina no tratamento das onicomicoses. ${ }^{19}$

Como algumas crianças podem ter dificuldade em deglutir os comprimidos, a terbinafina pode ser esma- gada e a cápsula de itraconazol aberta ao meio e o conteúdo misturado com alimentos..$^{30}$ Existem, igualmente, soluções orais de itraconazol e de fluconazol. ${ }^{30} \mathrm{En}$ quanto as cápsulas apresentam uma biodisponibilidade óptima quando ingerida juntamente com os alimentos, a solução oral de itraconazol deve ser tomada em jejum. ${ }^{30}$ No entanto, o seu uso não é recomendado em crianças por apresentar como excipiente a ciclodextrina. ${ }^{13}$

\section{Os diabéticos}

A prevalência das onicomicoses é maior em indivíduos diabéticos do que na população não diabética. ${ }^{24-31}$ Cerca de um terço dos diabéticos apresentam infecções fúngicas das unhas. ${ }^{24-31}$ Os diabéticos do sexo masculino têm um risco de onicomicose três vezes superior aos do sexo feminino. ${ }^{24-31}$

O pé diabético representa uma das complicações mais sérias da diabetes, contribuindo as infecções fúngicas das unhas para a gravidade deste. ${ }^{31}$

Devido às suas possíveis complicações, as onicomicoses conferem um risco superior aos doentes diabéticos, devendo ser tratadas. ${ }^{22,31}$ As consequências de não tratar esta condição em diabéticos podem ser mais graves do que em indivíduos saudáveis, incluindo a celulite, a perioníquia, a ulceração do leito ungueal e até a osteomielite. ${ }^{24-31}$ As menores abrasões da pele passam muitas vezes despercebidas nestes doentes devido às alterações da sensibilidade consequentes à neuropatia e às alterações circulatórias. ${ }^{24-31}$ Por outro lado, os diabéticos obesos ou com retinopatia podem ter dificuldade em dobrar-se ou em reparar em pequenas fissuras ou úlceras do pé. ${ }^{24} \mathrm{~A}$ retinopatia e a neuropatia periférica são factores de risco independentes para a onicomicose na diabetes. ${ }^{24}$ Outros factores incluem o défice de circulação periférica, a idade, a história familiar e a medicação com fármacos imunossupressores. ${ }^{24}$

Os indivíduos mais jovens podem sofrer de problemas de auto-estima que são agravados pela aparência das unhas, o que pode restringir as suas actividades sociais. ${ }^{31}$

As onicomicoses associam-se frequentemente a tinha do pé que, ao conduzir ao aparecimento de fissuras, serve de porta de entrada para as bactérias, devendo ser tratada. ${ }^{31}$

O tratamento das onicomicoses é semelhante ao dos indivíduos saudáveis. ${ }^{24-31}$ As terapêuticas tópicas têm 
limitações em alcançar o local da infecção e são adequadas apenas em certos doentes com onicomicose inicial ou leve, embora sejam comummente utilizadas como adjuvantes. ${ }^{31}$ Também podem ser úteis na onicomicose superficial. ${ }^{24}$

Os antifúngicos da família dos azóis, incluindo o itraconazol e o fluconazol provocam elevação dos níveis dos antidiabéticos orais. ${ }^{24}$ No entanto, o itraconazol oral é considerado eficaz e seguro no tratamento de doentes diabéticos com onicomicoses, assim como a terbinafina. ${ }^{24,31}$ A terbinafina é o fármaco de primeira linha no tratamento das onicomicoses. ${ }^{24}$ Contrariamente ao itraconazol, que apresenta um amplo espectro de actividade, a terbinafina é activa in vivo apenas na tinea un guium, não actuando contra espécies não dermatófitas como a Candida. ${ }^{24} \mathrm{~A}$ sua dose pode ter que ser ajustada em doentes com insuficiência renal. ${ }^{31}$

A avulsão cirúrgica das unhas deverá ser usada em diabéticos apenas em casos refractários ou quando a terapêutica oral está contra-indicada, devido ao risco aumentado de infecções secundárias, gangrena e má cicatrização. ${ }^{24}$

Os diabéticos de risco elevado, especialmente aqueles com neuropatia periférica ou doença vascular periférica, devem ser educados a observar os seus pés e pernas. ${ }^{20}$ É importante clarificá-los que não podem dar importância apenas ao desconforto ou à dor, dada a diminuição da sensibilidade. ${ }^{24}$

\section{Os indivíduos VIH-positivos}

A imunossupressão, como no caso da infecção pelo VIH, não conduz a um aumento da frequência de infecção por dermatófitos. ${ }^{4}$ Porém, a gravidade da doença e a probabilidade de recorrência são maiores. ${ }^{4}$

Há falta de estudos epidemiológicos acerca das infecções por dermatófitos em doentes com VIH, registando-se uma incidência semelhante à população em geral. ${ }^{32}$ A prevalência das epidermofitias nestes doentes tem vindo a diminuir, provavelmente devido à utilização generalizada da terapêutica anti-retroviral. ${ }^{32}$

A onicomicose subungueal proximal é uma excepção que ocorre quase exclusivamente em indivíduos imunocomprometidos. ${ }^{32}$

As infecções por dermatófitos em indivíduos VIHpositivos tendem a ser mais graves, atípicas e refractárias ao tratamento. ${ }^{32}$ Nestes, as onicomicoses envolvem frequentemente várias unhas dos pés. Nos doentes VIHpositivos com tinea pedis, o prurido e a dor ocorrem com pouca frequência, sendo a dor mais comum no caso de superinfecção bacteriana. ${ }^{32}$

Normalmente, as epidermofitias restringem-se à epiderme. ${ }^{32}$ Contudo, nos indivíduos com VIH, esta infecção pode tornar-se invasiva..$^{32} \mathrm{~A}$ apresentação mais usual de uma infecção profunda ou localmente invasiva manifesta-se pela erupção de nódulos junto ao local de infecção inicial, embora os abcessos, os micetomas e lesões atípicas também sejam possíveis. ${ }^{32} \mathrm{~A}$ causa é geralmente o T. rubrum..$^{32}$

As medicações antifúngicas tópicas são consideradas a primeira linha no tratamento da tinha. ${ }^{32}$ Quando não existe resposta deve recorrer-se à terapêutica sistémica, sendo o itraconazol e o fluconazol os fármacos mais usados. $^{32}$

As onicomicoses também requerem medicação oral, sendo a terbinafina e o itraconazol vulgarmente usados. ${ }^{32}$

É necessário ter em conta que estes doentes podem apresentar resistência aos antifúngicos após a sua utilização crónica para outras infecções fúngicas. ${ }^{32}$

Deve, igualmente, considerar-se a hipótese de interacções, como é o caso do itraconazol, que não pode ser administrado juntamente com os inibidores das proteases. $^{32}$

Uma descrição detalhada dos efeitos adversos e precauções a tomar aquando da administração de terapêutica antifúngica sistémica pode ser consultada no Quadro I.

\section{TESTES DIAGNÓSTICOS}

Um exame clínico cuidado é o primeiro e mais importante passo no diagnóstico das epidermofitias. ${ }^{7}$ Visto que muitas outras condições se assemelham às dermatofitoses, os exames laboratoriais são necessários para confirmar o diagnóstico. ${ }^{4} \mathrm{O}$ diagnóstico pode ser estabelecido através de um dos diversos exames: microscopia com hidróxido de potássio, cultura, lâmpada de Wood e biópsia. ${ }^{2}$

O exame microscópico hidróxido de potássio a $20 \%$ permite confirmar a presença de dermatófitos, tendo um excelente valor preditivo positivo. ${ }^{13}$ No entanto, permite apenas atestar a presença de dermatófitos, sendo a identificação da espécie possível apenas em cultura. ${ }^{4-5,19-20}$

A cultura diferencia os fungos dermatófitos dos não 
dermatófitos, o que pode alterar o tratamento. ${ }^{33} \mathrm{Tem}$ um papel limitado na avaliação e tratamento de uma suspeita de dermatofitose devido ao custo e ao consumo de tempo. ${ }^{3}$ No entanto, a colheita de material é indispensável se se pretender obter o diagnóstico micológico., ${ }^{5,26-27}$

$\mathrm{Na}$ prática clínica, a recolha de amostras para microscopia e cultura é aconselhada quando há necessidade de terapêutica oral, nomeadamente na tinea capitis e na tinea unguium; a infecção parece refractária ao tratamento inicial; ou o diagnóstico é incerto. ${ }^{33} \mathrm{~A}$ existência de um resultado positivo em apenas um destes é suficiente para iniciar a terapêutica. ${ }^{33}$ Quando ambos são negativos e existe uma forte suspeita clínica de infecção fúngica é recomendável repetir a colheita. ${ }^{33}$

Antes de se proceder à recolha de material é essencial retirar eventuais cremes que tenham sido aplicados. ${ }^{17,33}$

No couro cabeludo e na barba utiliza-se uma pinça de extremidades espatuladas para colher os cotos dos cabelos e os pêlos atingidos e quebrados..$^{5,12}$

Na pele glabra raspa-se o bordo activo das lesões ou as áreas de descamação com o bisturi, ou retira-se o tecto e o líquido das vesículas. ${ }^{5,17}$ São precisos cerca de 5 $\mathrm{mm}^{2}$ de pedaços de pele para microscopia e cultura. ${ }^{17,33}$

No caso de suspeita de onicomicose, as amostras podem obter-se directamente das regiões de hiperqueratose subungueal ou, no caso da tinea unguium superficial, raspando as zonas esbranquiçadas com uma lâmina. ${ }^{19-20,27,33}$ Se o material for seco e esfarelado, é possível utilizar algodão humedecido com água estéril. ${ }^{19} \mathrm{Os}$ fragmentos das unhas afectadas também podem ser usados..$^{19}$ Na colheita de material ungueal para cultura, deve-se proceder à desinfecção prévia com álcool etílico a 70\%, a fim de evitar a contaminação. ${ }^{19,28}$

As amostras devem ser enviadas ao laboratório comprimidas entre duas lâminas de vidro embrulhadas em papel não poroso a fim de evitar a secura. ${ }^{5}$ Devem ser mantidas à temperatura ambiente e não refrigeradas, pois as baixas temperaturas inibem o crescimento dos dermatófitos e a humidade facilita o crescimento de contaminantes. $^{27}$

Quanto à lâmpada de Wood, esta tem pouca utilidade nas tinhas devido ao número decrescente de fungos dermatófitos que fluorescem à luz ultravioleta. ${ }^{3}$ Exceptuam-se as tinhas do couro cabeludo causadas por $\mathrm{Mi}$ crosporum canis e Microsporum audouinii. ${ }^{3}$ Além disso, não existe lâmpada deWood na maioria dos centros de saúde, limitando o seu interesse em Medicina Geral e Familiar.

\section{AGRADECIMENTOS}

Agradeço ao Dr. Rui Fernandes Marcos, Assistente Hospitalar Graduado de Dermatologia do Hospital de Egas Moniz, pela cedência de imagens do seu arquivo pessoal, revisão do artigo e apoio constante na sua realização.

\section{REFÊRENCIAS BIBLIOGRÁFICAS}

1. Ameen M. Epidemiology of superficial fungal infections. Clin Dermatol 2010 Mar 4; 28 (2): 197-201.

2. Hainer BL. Dermatophyte Infections. Am Fam Physician 2003 Jan; 67 (1): 101-8.

3. Andrews MD, Burns M. Common tinea infections in children. Am Fam Physician 2008 May 15; 77 (10): 1415-20.

4. Sobera JO, Elewski BE. Fungal Diseases. In: Bolognia JL, Jorizzo JL, Rapini RP, editors. Dermatology. $2^{\mathrm{a}}$ ed. Madrid: Mosby Elsevier; 2008. p. 1135-48.

5. Cabrita J. Micoses. In: Esteves JA, Baptista AP, Rodrigo FG, Gomes MM, editores. Dermatologia. $2^{\mathrm{a}}$ ed. Lisboa: Fundação Calouste Gulbenkian; 1992. p. 1063-96

6. Gupta AK, Ryder JE, Chow M, Cooper EA. Dermatophytosis: the management of fungal infections. Skinmed 2005 Sep-Oct; 4 (5): 305-10.

7. Weinstein A, Berman B. Topical treatment of common superficial tinea infections. Am Fam Physician 2002 May 15; 65 (10): 2095-102.

8. Cabrita J, Esteves J, Sequeira H. Dermatophytes in Portugal (19721981). Mycopathologia 1984 Feb 15; 84 (2-3): 159-64.

9. Sotiriadis DK. Hair and nail disorders of childhood. Expert Rev Dermatol 2008; 3 (6): 677-90.

10. Craft N, Shallow WV, Management of superficial fungal infections. In: Goroll AH, Mulley AG, editors. Primary Care Medicine: Office Evaluation and Management of the Adult Patient. Philadelphia: Lippincott Williams \& Wilkins; 2006. p. 1376-7.

11. Dermatology. In: Rakel RE. Rakel's Textbook of Family Medicine. 7th ed. Philadelphia:W.B. Saunders; 2007. p. 974-6.

12. Higgins EM, Fuller LC, Smith CH. Guidelines for the management of tinea capitis. Br J Dermatol 2000 Jul: 143 (1): 53-8.

13. Sethi A,Antaya A. Systemic antifungal therapy for cutaneous infections in children. Pediatr Infect Dis J 2006 Jul; 25 (7): 643-4.

14. Clinical Knowledge Summaries. Fungal skin infection - scalp; 2009 May. Disponível em: http://www.cks.nhs.uk/fungal_skin_infection_scalp [acedido em 29/10/2010]

15. Hubbard TW. The predictive value of symptoms in diagnosing childhood tinea capitis. Arch Pediatr Adolesc Med 1999 Nov; 153 (11): 1150-3.

16. Gupta AK, Cooper EA. Update in antifungal therapy of dermatophytosis. Mycopathologia 2008 Nov-Dec; 166 (5-6): 353-67.

17. Clinical Knowledge Summaries. Fungal skin infection: body and groin. 2009 May. Disponível em: http://www.cks.nhs.uk/fungal_skin_infection_body_and_groin [acedido em 29/09/2010].

18. Clinical Knowledge Summaries. Fungal Skin Infection: foot. 2009 April. Disponível em: http://www.cks.nhs.uk/fungal_skin_infection_foot [acedido em 29/09/2010].

19. Welsh O,Vera-Cabrera L, Welsh E. Onychomycosis. Clin Dermatol 2010 Mar; 28 (2): 151-9.

20. Roberts DT, Taylor WD, Boyle J; British Association of Dermatologists. Guidelines for treatment of onychomycosis. Br J Dermatol. 2003 Mar; 148 (3): 402-10.

21. Oakley A, Hamilton T, Management of fungal nail infections. Best Pract J 2009 Fev; 19: 18-23. Disponível em: URL: http://www.bpac.org.nz/ 
magazine/2009/february/docs/bpj19_fungalnail_pages_18-23.pdf [acedido em 14/10/2010].

22. Loo DS. Onychomycosis in the elderly: drug treatment options. Drugs Aging 2007; 24 (4): 293-302.

23. Rodgers P, Bassler M. Treating onychomycosis. Am Fam Physician 2001 Feb 15; 63 (4): 663-72, 677-8.

24. Winston JA, Miller JL. Treatment of Onychomycosis in Diabetic Patients. Clin Diabetes 2006 Oct; 24 (6): 160-6.

25. de Berker D. Clinical practice: fungal nail disease. N Engl J Med 2009 May 14; 360 (20): 2108-16

26. Scher RK, Baran R. Onychomycosis in clinical practice: factors contributing to recurrence. Br J Dermatol 2003 Sep; 149 Suppl 65: 5-9.

27. Jaffe R. Onychomycosis: recognition, diagnosis, and management. Arch Fam Med 1998 Nov-Dec; 7 (6): 587-92.

28. Clinical Knowledge Summaries. Fungal Nail Infection (onychomycosis) 2009 May. Disponível em: http://www.cks.nhs.uk/fungal_nail_infection/view_whole_topic [acedido em 29/09/2010].

29. Angello JT, Voytovich RM, Jan SA. A cost/efficacy analysis of oral antifungals indicated for the treatment of onychomycosis: griseofulvin, itraconazole, and terbinafine. Am J Manag Care 1997 Mar; 3 (3): 442-50.

30. Gupta AK, Skinner AR. Onychomycosis in children: a brief overview with treatment strategies. Pediatr Dermatol 2004 Jan-Feb; 21 (1): 74-9.

31. Gupta AK, Humke S. The prevalence and management of onychomycosis in diabetic patients. Eur J Dermatol 2000 Jul-Aug; 10 (5): 379-84.

32. Saedi N, Rofagha R, Zachary C. Five important dermatologic papers from the recent nondermatology literature. Expert Rev Dermatol 2009
Oct; 4 (5): 435-7.

33. Health Protection Agency 2009. Fungal nail \& skin infections: diagnosis \& laboratory investigation - Quick reference guide for primary care. Disponível em: http://www.hpa.org.uk/web/HPAwebFile/HPAweb_C/1240294785726 [acedido em 26/09/2010].

34. Valdigem GL, Pereira T, Macedo C, Duarte ML. Oliveira P, Ludovico P, et al. A twenty-year survey of dermatophytoses in Braga, Portugal. Int J Dermatol 2006 Jul; 45 (7): 822-7.

35. Baran R, Sigurgeirsson B, de Berker D, Kaufmann R, Lecha M, Faergemann J, et al. A multicentre, randomized, controlled study of the efficacy, safety and cost-effectiveness of a combination therapy with amorolfine nail lacquer and oral terbinafine compared with oral terbinafine alone for the treatment of onychomycosis with matrix involvement. Br J Dermatol 2007 Jul; 157 (1): 149-57.

\section{CONFLITOS DE INTERESSES}

A autora declara não existir conflito de interesses na elaboração do artigo.

\section{ENDEREÇO PARA CORRESPONDÊNCIA}

Diana Tomaz Fonseca da Silva

Rua Infante D. Henrique n. ${ }^{\circ} 3$, 1. $^{\circ}$ esq. ${ }^{\circ}$ 2685-213 Portela LRS

diana.tomas@hotmail.com

Recebido em 04/10/2010

Aceite para publicação em 15/02/2011

\section{ABSTRACT}

\section{IS IT A FUNGUS?}

Superficial mycoses are believed to affect $20 \%$ to $25 \%$ of the world's population and its incidence continues to increase. They are mainly caused by dermatophytes, which are fungi that require keratin for their growth. Skin lesions produced by these fungi are named dermatomycosis, dermatophytosis, ringworm or tinea.

In Family Medicine, the clinician often has to deal with questions such as: «Dr., some weird spots have appeared in my skin, is it a fungus?». Frequently it is difficult to decide whether it is appropriate to initiate systemic therapy, particularly in higher risk patients, such as the polimedicated, the immunodepressed, the diabetics and the children.

This article intends to review dermatophyte infections, focusing especially on their therapeutic management.

Tinea is generally classified according to its anatomic location: tinea capitis is located on the scalp, tinea pedis on the feet, tinea corporis on the body, tinea cruris on the groin, and tinea unguium on the nails.

A thorough clinical examination is the primary and most important step to diagnose a dermatophyte infection. Yet, it can be established using potassium hydroxide microscopy, fungal culture, Wood's lamp examination or histologic examination. Samples should be taken for microscopy and culture in severe or extensive skin fungal infections, when oral treatment is being considered, when skin infections are refractory to initial treatment, or when the diagnosis is uncertain.

Although topical treatment is enough in the majority of dermatomycosis, oral antifungals are recommended when considering tinea capitis, tinea barbae and tinea unguium. Cure rates are higher and treatment courses are shorter with topical allylamines than with azoles.

Terbinafine, itraconazole and fluconazole formulations are the most commonly used antifungals in systemic therapy.

Keywords: Dermatomycosis; Diagnosis; Prevention; Therapeutics; Primary Health Care. 